\title{
LOCUSTS AND GRASSHOPPERS
}

A SPECIAL session, held on September 5 , of Section D (Zoology) of the British Association at the Birmingham meeting was devoted to a symposium on the locust and grasshopper problem.

The subject was introduced by Dr. B. P. Uvarov, of the Anti-Locust Research Centre, who pointed out that the steady increase in world population makes it essential not only to grow more food, but also to protect crops from losses caused by insects. Before the Second World War, locusts and grasshoppers were estimated to cause an average annual loss of food crops to the value of some 15 million pounds; it would not be an exaggeration to double that figure now, owing to the rise in prices. Although this is the oldest entomological problem, it is still largely unsolved. In the past, its solution was hampered by the periodicity of locust plagues, which made it impossible to obtain support for continuous research. Since 1929, however, British anti-locust research has been organised on the basis of continuity, and of wide, if largely informal, international collaboration.

The locust problem has many aspects, its main ramifications being: causes of vast fluctuations in numbers of the insects; transformation of locust phases from a relatively harmless solitary phase to the swarming one; migrations over wide areas; effects of agricultural practices, etc. Modern developments in insecticides and machinery make locust killing a relatively simple technical operation; the difficulty is in the organisation, as local efforts are of little use owing to the mobility of the insects. Successful antilocust campaigns were conducted during the Second World War in Africa and the Middle East, and their success was due to overall planning and co-ordination of the efforts of many countries ; such efforts can be repeated, but they can achieve only temporary successes. In the case of grasshoppers in North America, chemical control is highly successful; but operations have to be repeated every year, at an ever-increasing cost.

All such successes are temporary, but a lasting solution of the problem is also possible. Investigations of the past twenty years have shown that locust plagues arise in some relatively restricted areas from which swarms gradually spread over whole continents. Such 'outbreak areas' have been defined in the case of two African locusts, and they are now kept under continuous observation and control by small inter. national organisations. The initial stages of at least two plagues have been noticed in time and suppressed before they could develop. It is now hoped that a careful study of the conditions which favour the initial swarming in the outbreak areas may provide the means of preventing plagues by altering the conditions in a sense unfavourable to swarming. This may require long study and experiment, but the prospect of complete prevention of plagues is sufficiently attractive to justify the work. Thus, while the locust problem cannot yet be considered as solved, it is known to be soluble, and the way towards its solution is now fairly clear. Final success depends largely on the effective international organisation of both research and control, and the most promising form of international co-operation is offered by regional organisations, each concerned with a single species of locust and supported by all countries subject to invasions by that species.

With regard to research, Dr. Uvarov particularly insisted that the problem cannot be solved by entomologists alone, but requires their close collaboration with physiologists, biochemists, meteorologists, geographers and agronomists.

Dr. Peggy Ellis (University College, London) then presented a very lively account of her experimental work on movement in locust hoppers. In the field, hoppers of the gregarious phase are known to undertake spectacular marching in large bands, while those of the solitary phase spend most of the day resting on vegetation. It has proved possible to induce regular marching in cages and thus to study it experimentally. It was found that marching is favoured by medium temperatures $\left(86-95^{\circ} \mathrm{F}\right.$.), radiant heat, air movement and absence of food in the cage ; the effect of hunger was very pronounced. Marching activity is very much dependent on the density of hopper groups, suggesting mutual stimulation. Hoppers of the phase solitaria could be induced to march when placed in a group, but less persistently than gregarious hoppers. Although vigorous marching of starving hoppers in the field may increase their chances of finding food, they often march into the desert, and there is no evidence that marching is a quest for food.

Miss Z. Waloff (Anti-Locust Research Centre) followed with a review of recent work on locust migrations. Although locusts are known to have migrated in swarms in ancient times, their invasions have, until recently, been regarded as unpredictable. For the past twenty years, however, reports of swarm movements and breeding of three economically important species, the desert or Bible locust, the African migratory locust and the red locust, have been collected at the Anti-Locust Research Centre, London, where they are mapped and analysed. The cartographical analysis has led to the delimitation of their outbreak and invasion areas, of the seasonal distribution of breeding, which is closely linked up with the seasonal incidence of rain, and to the establishment of the fact that the directions of migrations follow definite seasonal patterns. On the basis of these findings, it is now possible to prepare generalized forecasts of the probable movements of swarms, and to warn threatened countries well in advance of the actual appearance of the swarms.

The establishment of the seasonal patterns of migration raised the problem of the factors to which they might be due, and in particular of those which affect flying activity and the direction of movement. Such information is required not only for understanding the phenomenon of migration, but also for short-range forecasting of swarm movements in connexion with the use of mechanized control methods carried out by mobile units against mobile winged locusts.

Recent field-work in Africa on the behaviour of desert locust swarms has shown that migration is greatly affected by current weather conditions. Sunshine has a profound effect on flying activity, and in its presence locusts are able to migrate actively at air temperatures at which, but for the sun; they would 
be completely immobilized. The effect of solar radiation may be responsible for the ability of locust swarms to migrate in conditions as contrasted as those around the Red Sea in summer and the Moroccan highlands in winter.

The height at which locusts fly and the structure of the swarms are closely related to the intensity of thermal convection currents such as develop over heated ground and are known to provide a source of lift to soaring birds and sailplanes. In the absence of convection, flying locusts keep low above the ground and fly in flat stratiform swarms. When convection is present, the swarms resemble cumulus clouds and are described as cumuliform. When convection is vigorous, locusts may be lifted several thousand feet above the ground.

Not only the vertical convection currents but also the horizontal winds have an important transporting effect and affect the direction of movement. The flying speed of locusts is about $11 \mathrm{~m} . \mathrm{p}$.h., and at windspeeds above this value the direction of displacement is down-wind regardless of the course on which the locusts fly. When winds are light, the direction of displacement is related to the course adopted by locusts, and there is evidence to suggest that wind is concerned in determining the direction of this course.

It is clear from field observations that the problems involved in diurnal movements and in large-scale geographical displacements cannot be solved unless equal attention is paid to locust behaviour and to the dynamic medium in which they move, and investigations on migrations call for close co-operation between entomologists and meteorologists.

Dr. J. S. Kennedy (Unit of Insect Physiology, Cambridge), in his address, concentrated attention on the problem of direction in migrations of the desert locust. The most characteristic feature of the behaviour of migrants is their persistent locomotion, and when one watches them pressing steadily on, they seem directed by some mysterious inner force. Nobody has taken this interpretation quite literally, but it has had the effect of turning the search for directing forces away from the environment of the migrants. Yet there is now sufficient evidence that flying locusts are by no means oblivious of their immediate surroundings, and that the individual's direction is continually being regulated by stimuli from other individuals, from the sun, the wind and so on. There is good reason to suppose the wind to be the key factor to the resultant long-range trends in migrations. It appears to have an important orienting and transporting action, depending on its strength and the height at which the insects are flying. The migrant seems to be making a complicated series of regulatory responses, probably visual ; they are necessitated by the fact that the medium in which the locust carries out its persistent locomotion is the air, which itself moves. The success in this 'ding-dong battle' between insects and wind sometimes goes to the insects, when their movements have an up-wind tendency, and sometimes to the wind, when they go with it. A theory of how longrange directions may be determined can, therefore, be constructed, with the wind as the primary factor, while other factors, such as temperature and light, decide what kind of directing action the wind will actually exert at any particular time and place.

Dr. O. W. Richards (Imperial College of Science and Technology, London) dealt with the important problem of estimation of numbers in a grasshopper population. Working on British grasshoppers, it has been possible to develop techniques not only for estimating the total population, but also to follow changes in its age structure, mortality in different instars and so on.

In the discussion that followed, Dr. V. B. Wigglesworth (president of Section D) asked why the establishment of permanent control of the desert locust had been slower than that of the migratory and the red locusts. Dr. Uvarov explained that the area of the desert locust is very much larger and comprises some of the most inhospitable regions, many of them difficult of access for physical and political reasons. This area extends over some twenty-five countries, with governments so widely different that it is almost impossible to arrange for satisfactory co-operation. The result is that, while the other two locusts are under control, a new plague of the desert locust is actually developing; this may provide a salutary lesson to those countries which have so far failed to see the advantages of common action.

Prof. G. C. Varley (Oxford) suggested that an evolutionary approach to the migration problem might provide valuable clues, but Dr. Uvarov maintained that it is best to start by studying the phenomenon in all its aspects, rather than by theorizing while factual knowledge is still inadequate.

Captain T. Dannreuther provided some examples of long-range migrations by Lepidoptera which, in his opinion, cannot be explained by reference to climatic factors; Miss Waloff suggested, however, that such cases might usefully be analysed against synoptic weather data.

B. P. Uvarov

\section{CHEMICAL COMPOSITION OF NEWLY BORN MAMMALS}

\section{By E. M. WIDDOWSON}

Medical Research Council Department of Experimental Medicine, Cambridge

$T$

HE chemical composition of the fotal and newly born mammal has interested many investigators in the past hundred years, but no one ever appears to have made a direct comparison of the full-term human baby with the newly born of other mammalian species. Von Bezold ${ }^{1,2}$, who was the first to make a chemical analysis of a human foetus, is, in fact, the only one who has analysed both human and other species, and his human fotus weighed only $523 \mathrm{gm}$.

As part of a study of some chemical aspects of growth, six full-term human babies ${ }^{3}$ and a number of newly born mice, rats, rabbits, guinea pigs, cats and pigs have been analysed. One grey seal (Halichorus gryphus) was also investigated. This was found dead

Table 1. Water, protein and fat in newly born mammals

\begin{tabular}{|c|c|c|c|c|c|}
\hline \multirow{2}{*}{ Species } & \multirow{2}{*}{$\begin{array}{c}\text { No. } \\
\text { analysed }\end{array}$} & \multirow{2}{*}{$\begin{array}{c}\text { Average } \\
\text { weight } \\
\text { gm. }\end{array}$} & \multicolumn{3}{|c|}{$\begin{array}{c}\text { gm. per } 100 \mathrm{gm} . \text { fresh } \\
\text { weight }\end{array}$} \\
\hline & & & Water & Protein & Fat \\
\hline $\begin{array}{l}\text { Human } \\
\text { Pig } \\
\text { Cat } \\
\text { Rabbit } \\
\text { Guinea pig } \\
\text { Rat } \\
\text { Mouse }\end{array}$ & $\begin{array}{r}6 \\
16 \\
5 \\
12 \\
10 \\
68 \\
68\end{array}$ & $\begin{array}{c}3,564 \\
1,460 \\
118 \cdot 0 \\
54 \cdot 0 \\
80 \cdot 1 \\
5 \cdot 85 \\
1 \cdot 55\end{array}$ & $\begin{array}{l}69 \cdot 1 \\
84 \cdot 1 \\
80 \cdot 7 \\
84 \cdot 6 \\
70 \cdot 9 \\
86 \cdot 0 \\
83 \cdot 3\end{array}$ & $\begin{array}{l}11 \cdot 9 \\
11 \cdot 3 \\
14 \cdot 9 \\
11 \cdot 1 \\
14 \cdot 9 \\
10 \cdot 8 \\
12 \cdot 5\end{array}$ & $\begin{array}{r}16 \cdot 1 \\
1 \cdot 1 \\
1 \cdot 8 \\
2 \cdot 0 \\
10 \cdot 1 \\
1 \cdot 1 \\
2 \cdot 1\end{array}$ \\
\hline
\end{tabular}

